\title{
VERSITA
}

\section{ECOLOGICAL NETWORKS ARE AN ISSUE FOR ALL OF US.}

\author{
ROB JONGMAN
}

Alterra, Wageningen UR, Postbox 47, 6700AA, Wageningen, The Netherlands, rob.jongman@wur.nl

Received: $12^{\text {th }}$ March 2008, Accepted: $31^{\text {st }}$ October 2008

\section{INTRODUCTION}

The concept of ecological networks is not new. Ecological networks have been developed in several European countries, including in Estonia during the 1970s and 1980s and in former Czechoslovakia during the 1980s. In these countries, a strong tradition in land-use planning had created the institutional environment for allocating functions at the landscape scale and habitats were becoming increasingly fragmented due to economic development. We now recognise this as the translation of landscape ecological knowledge in homogenisation and fragmentation processes in the landscapes of Europe that diminished ecosystem functions and natural populations. Fragmentation explains much of the decline in natural species, and we now realize that, for many natural species, existing nature reserves and national parks are too small (Somma, 2006). The concept of ecological connectivity is implicit in several international conventions (e.g. Ramsar convention, Bern Convention), European agreements (Habitats and Species directives), and related EU policy implementation (Natura 2000). It has also become operational in national and European strategies (National Ecological Networks, the Pan-European Ecological Network and Pan European Biological and Landscape Diversity Strategy (PEBLDS).

The initial aim of establishing ecological networks is predominantly protection of nature and biodiversity. Its development is stimulated by science and nature management practice. For example (in Rientjes and Roumelioti, 2003), in PEBLDS, the Pan-European Ecological Network aims to ensure that:

- A full range of good quality ecosystems, habitats, species and landscapes of European importance are conserved;

- Habitats are large enough to guarantee key species a favourable conservation status;

- There are sufficient opportunities for dispersal and migration of species;

- Damaged parts of key environmental systems are restored;

- The key environmental systems are buffered from threats.

In most countries, the traditional identification of nature reserves and national parks did not require involvement of the general public, as these areas separated "undisturbed" nature from intensive land uses. However, this division between nature and other land use appears - at least in Europe - to be no longer sustainable. Land-use practices exist that traditionally make use of nature in a sustainable way and contribute to the survival of species. Examples include reed cutting in marshland and transhumance farming in mountain systems. These practices are disappearing, however, as they cannot compete economically and people are 
less and less interested in doing such heavy work. As land use changes, many species can no longer survive on the abandoned land, the remnants of natural land left behind, or on land where its use is subject to intensification. In addition, the survival of many species is threatened by increasing infrastructure and urbanisation. Ecological networks, or green networks, can provide a solution to the problems of intensifying land use and fragmentation, enabling natural populations of species and threatened habitats to survive.

The meaning and the application of the ecological network concept has changed over the past decade, with emphasis shifting from nature protection towards sustainable development for a region as a whole that integrates biodiversity issues. The observed change in thinking originates from the discourse in the international policy arena of the Convention on Biodiversity, the World Summit on Sustainable Development, and the Millennium Development Goals, which perceived the environment as making a contribution to sustainable development, rather than as something with intrinsic value to be protected from use. Implementation of these international agendas is increasingly guided by the ecosystem approach. This approach can be regarded as a strategy for the management of land, water and living resources that promotes conservation and sustainable use in an equitable way. At the heart of the approach is the awareness that without the effective and sustainable management of ecosystems there can be no economic development that generates sustainable human and social welfare. Equally, without the full engagement of diverse sectors in the economy and society in the management of ecosystems, there can be no effective biodiversity conservation. In this sense, the ecosystem approach is a framework for holistic decision-making and action (Bennett, 2004). This shift in emphasis runs parallel with changing paradigms in protected area management that have moved, over the years, from "strictly nature oriented" to "nature and people oriented" (Phillips, 2003). In some European countries (e.g. Portugal), as well as in the USA, this approach is called greenway planning, which aims to integrate local interests with biodiversity conservation and building on the tradition of greenbelt planning and parkway planning (Jongman and Pungetti, 2004).

The definition of an ecological network of Bennett and Wit (2001) is in line with this paradigm shift: "A coherent system of natural and/or semi-natural landscape elements that is configured and managed with the objective of maintaining or restoring ecological functions as a means to conserve biodiversity while also providing appropriate opportunities for the sustainable use of natural resources".

One consequence of perceiving an ecological network as a means towards sustainable development is the increasing number and diversity of stakeholders and land-use interests that need to be incorporated into the design and that should be part of the management process. In addition, it is evident that the institutionalisation of such a landscape change will greatly benefit from the overall support of the stakeholders, or as Bennett (2004) puts it: "No programme of the breadth and ambition of an ecological network can achieve results without the active support of local communities and key stakeholders."

\section{PUBLIC SUPPORT FOR ECOLOGICAL NETWORKS IN EUROPE}

The plans for the further development of ecological networks in Europe are ambitious. The $5^{\text {th }}$ Ministerial Conference "Environment of Europe" in Sofia concluded that "by 2008, all core areas of the Pan-European Ecological Network will be adequately conserved and the Pan-European Ecological Network will give guidance to all major national, regional and international land-use and planning policies as well as to the operations of relevant 
economic and financial sectors." It is obvious that these targets cannot be met in 2008 for the European Union as a whole. They also require active cooperation of the relevant landuse sectors, such as agriculture and forestry, and local and regional planning authorities. Ecological networks extend beyond the "traditional" domain of nature conservation (protected areas), as they include vast stretches of land over which nature conservation authorities and non-governmental organisations (NGOs) have no "jurisdiction". The targets, therefore, can only be realized in partnerships between the conservation sector (government and NGO) and the various stakeholders involved (ECNC, 2004).

The arguments and targets need to include other benefits for society, or "ecological services". Partnerships are built on mutual interests. The interests of the conservation sector are believed to be clear, i.e. conservation of biodiversity. Who are the other partners (stakeholders) and what are their interests? An ecological network as a landscape mosaic, and perceived as part of an integrated regional or national plan, can only be sustained with active support of the various stakeholders. Generating active stakeholder support for ecological networks has taken many forms. Making clear what the benefits are (the ecosystem services it provides) is a key element in this.

In Estonia, the approach to gain support for the ecological network took the form of meetings and public campaigns (Sepp and Kaasik, 2002) with emphasis placed on:

- The multifunctional nature of ecological networks (e.g. increased environmental health conditions, recreational opportunities);

- Conservation of "flagship species" to highlight the importance of biodiversity conservation; and

- The accommodation of semi-natural habitats or other "use areas" that allow traditional farming practices in the networks.

In many cases, such as the Yellowstone-to-Yukon (Y2Y) ecological network in North America, the initiative does not come from the government. As with most North American greenway plans, Y2Y is very much a grassroots initiative, enjoying support from a large variety of NGOs and other civil society organisations (360 in total) and with the objective of ensuring that the eco-region continues to support natural and human communities. In a few states in the USA (e.g. Florida and Georgia), the states have embraced these grassroots plans and developed them into the Statewide Greenway Plan, which is based on the integration of biodiversity and civil interest issues.

What these cases have in common is that they focus not only on the conservation of biodiversity but also accommodate the exploitation and consumption of natural resources (Ahern, 2004). Serious efforts are made both to buffer sites of high conservation value from potentially damaging forms of land use and to find ways of reconciling the exploitation of natural resources with biodiversity conservation (Bennett and Wit, 2001).

\section{WHAT WOULD BE THE BENEFITS OF ECOLOGICAL NETWORKS?}

The eastern section of the Dutch National Ecological Network (NEN) has multifunctional objectives. Conservation and restoration of nature and biodiversity are priorities, but they are not the only objectives of the NEN. To make a large demand for space in the densely populated Netherlands can only be justified if it also provides a solution for other problems and needs, such as: 
- Completion of environmental objectives through the production of clean water, water management, sustainable use of natural resources (such as timber), and the absorption of $\mathrm{CO}_{2}$;

- Protection of important rural, cultural-historical, archaeological and geological values, fulfilling - under certain conditions - important recreational functions, sustainable agriculture and fisheries and transport over water (under certain conditions);

- Providing an attractive environment for living and business locations by maintaining highly-valued qualities such as green space and tranquillity;

- $\quad$ Provide space for people to relax and experience nature.

Meeting the requirements of nature, while at the same time taking into account societal and stakeholders' wishes, creates public support and willingness of third parties to invest in these areas. The public is prepared to pay taxes and fees; farmers (sometimes against payment of conservation subsidies) are willing to consider adapted land management options, and owners of country estates and small businesses are interested in investment in nature (Ministry of ANF, 2004).

Examples of tangible benefits in Gelderland (Eastern Netherlands) include:

- Investments in nature-based tourism and recreation that generate employment and incomes;

- Nature, as a catalyst for investment, prompts estate agents, water utilities and sand extraction companies to expand the acreage of land under conservation management, thereby adding to the value of the ecological network while boosting their production and profit;

- The enhanced value of nature allows the introduction of innovative and self-sustaining payment mechanisms for farmers to maintain environmentally valuable landscapes (from growing maize to growing nature);

- The natural landscape provides clean drinking water and increasingly allows temporary storage of excess river water that may otherwise threaten low-lying population centres.

Though it may be exaggerating a little, in line with recent thinking of that "nature has to pay for itself", a multifunctional ecological network may, in some cases, become an opportunity for rural development rather than a (short-term) cost to society. Appropriate planning and control would ensure rural development that is sustainable and, as such, contributes to the natural resources that development depends upon - truly a win-win scenario.

\section{STAKEHOLDER COOPERATION IN CONSERVATION ISSUES}

In cases where priorities for rural development are considered more important than the need for nature conservation, joining forces is an important way to achieve both goals. In the Hungarian Puszta, a group of researchers and local NGOs in the field of nature conservation and local development have initiated activities towards conserving agricultural practices, cultural heritage and nature. The initiative makes use of management measures such as Environmentally Sensitive Areas schemes, development of a rural development 
plan, and an ecological corridor along one of the streams in the area (Csincse). Conditions have been created for alternative incomes in an environmentally friendly manner, as well as for education through an information centre which aims to educate visitors and children.

This project was a grassroots initiative. Enthusiasm, private initiatives and endurance have been the driving forces. In this way, the area is an important example of how small opportunities can lead to regionally important initiatives. Important in this case is that these local initiatives have been recognised and supported by national and international organisations, including donors. The Kesznyétén Eurograssland project has lead to both rural development as well as nature conservation though ecological restoration and corridor development.

This example shows that an ecological network as a landscape mosaic with both biodiversity conservation and sustainable use objectives cannot easily be applied as a planning instrument when the aim is to optimise the balance between the objectives and to engage all relevant stakeholders. In this case, an adequate institutional context is required. Working at the landscape or regional scale involves long-term processes, operating across an array of administrative units, and involvement of a large number and wide range of stakeholders. It also depends heavily on a harmonised institutional setting that should be conducive to stakeholder involvement, e.g. respected rule of law, robust zoning arrangements, effective enforcement procedures, financial security for corporate stakeholders, and clearly defined public and private ownership patterns (Bennett, 2004; Somma, 2004).

Multi-stakeholder organisations, platforms or networks may be required to ensure the delivery of results that were previously the domain of narrow-focussed (typically environmental) agencies (Miller, 1996). The foundation of the actual implementation of an ecological network requires a shared vision amongst the stakeholders. The vision needs to foster stakeholder participation. This again requires a flexible strategy to make use of positive action in a region or community in order to join forces in cases of common interest, and planners have to be aware of the potential range of social, environmental and economic information at a local, regional and national scale. Information about the importance of ecosystem goods and services may be required to mobilise public support for the network and to let local stakeholders participate meaningfully in the decisions. The ecological network provides environmental goods and services that have direct-use values, such as timber, game, recreation and human habitat, as well as indirect-use values, such as watershed protection, climate regulation, erosion control and maintenance of biodiversity. The possible uses have different meanings for different stakeholders and, in order to facilitate decision-making about the importance of an ecosystem, it is vital to engage in valuation of these goods and services to allow trade-offs (Lette and Rozemeijer, 2005).

\section{CONCLUSIONS}

Notwithstanding the fact that every design process for an ecological network will be unique and needs to be adapted to the specific needs of the situation, it is possible to introduce an approach towards designing such a process.

First and foremost, it is necessary to be clear of the underlying assumptions. This means, for example, tackling fundamental issues, such as the benefits of planning and management of an ecological network with stakeholder involvement and the benefits from public support for ecological networks. Secondly, it is critical to have a thorough understanding of the situation in which the process will take place. Thirdly, a broad range of methodologies, 
methods and tools need to be drawn upon, adapted, and linked together in the required process. The four phases of the process are:

1. Setting-up. Clarify the reasons for an MSP; undertake an initial situation analysis (issues, stakeholders, institutions and power and politics); establish an interim steering body; build stakeholder support; establish the scope, mandate and expectations for the MSP; outline the general process, time frame, institutional requirements and resource needs.

2. Planning strategically. Build stakeholders' understandings of one another's values, motivations, concerns and interests; generate visions for the future; identify issues, problems and opportunities; examine scenarios and feasible options; make decisions and agree on key strategies; set objectives, identify actions, time frames and responsibilities; document and communicate planning outcomes.

3. Implementing and managing. Develop integrated initiatives and detailed action plans; secure resources and technical support; develop the capacities of stakeholders; establish required management structures and procedures; manage implementation processes; maintain the commitment of stakeholders.

4. Learning, monitoring and adapting. Create a learning culture and environment; define success criteria (performance questions and indicators); develop and implement monitoring mechanisms; review, evaluate and discuss progress and capture lessons learned; feed lessons learned back into strategies and implementation procedures.

It is argued in this paper that the investment put into designing and facilitating multistakeholder processes for the planning and management of ecological networks pays off in terms of enhanced public support for these networks, enhanced coordination with other regional development planning initiatives, benefits from a multi-disciplinary approach, and, as a result, maintenance of their integrity.

\section{REFERENCES}

Ahern, J. (2004). Greenways in the USA: theory, trends and prospects. In: Jongman, R.H.G., Pungetti, G. (Eds.): Ecological networks and greenways, concept, design and implementation. pp 34-55. Cambridge University Press,

Bennett, G. (2004). Integrating biodiversity conservation and sustainable use, lessons learnt from ecological networks. IUCN Gland.

Bennett, G., Wit, P. (2001). The development and application of ecological networks, a review of proposals, plans and programmes. IUCN/AIDEnvironment.

ECNC (2004). The Pan-European Ecological Network and People. Background paper as well as "Conclusions and Recommendations" of the 2004 seminar on "People and PEEN" in The Hague, the Netherlands (ECNC/LNV).

Jongman, R.H.G., Pungetti, G.P. (2004). Ecological networks and greenways, concept, design and implementation. Cambridge University Press. 
Lette, H., Rozemeijer, N. (2005). Broadening and diversifying the financial basis for sustainable forest management and nature conservation. IAC/WUR, the Netherlands.

Miller, K. (1996). Balancing the scales: guidelines for increasing biodiversity's chances through bioregional management. WRI, Washington, D.C.

Ministry of ANF (2004). Ecological networks: experiences in the Netherlands. "A joint responsibility for connectivity". LNV Working paper.

Phillips, A. (2003). Turning ideas on their head, the new paradigm for protected areas. IUCN.

Rientjes, S., Roumelioti, K. (2003). Support for ecological networks in European nature conservation, an indicative social map. ECNC.

Sepp, K., Kaasik, A. (2002). Development of national ecological networks in the Baltic countries in the framework of the Pan-European Ecological network. IUCN Central Europe.

Somma, D., Aued, M.B. \& Bachman, L. (2004). The ecological Networks development in the Yungas, Argentina: planning, economic and social aspects. In: Jongman R.H.G., Pungetti G. (Eds.): Ecological networks and greenways, concept, design and implementation. pp 251-269. Cambridge University Press, 